\title{
ANÁLISE ESTILÍSTICA DA TRADUÇÃO PORTUGUESA DE DE JOODSE MESSIAS DE A.GRUNBERG: TRANSCULTURALIDADE DA IRONIA
}

\author{
Andreia Carita \\ Universidade de Utreque/Holanda \\ andreiacarita@hotmail.com
}

\begin{abstract}
Resumo: Este artigo visou a compreensão da parte que a linguagem desempenha na criação de significado e efeito textuais. Para tal, foram analisados extractos da obra neerlandesa De joodse messias de Arnon Grunberg. O objectivo foi elaborar uma comparação ao nível estilístico entre esta obra neerlandesa e uma tradução em Português. Elementos como a ironia e temas recorrentes na literatura neerlandesa como a identidade dos judeus e a Segunda Guerra Mundial não são fáceis de transpor para uma tradução. Foi investigado o modo como esses elementos específicos da cultura holandesa poderiam ser recebidos pelos leitores portugueses. Por fim, foi avaliada a qualidade da tradução numa perspectiva crítica.

Palavras-chave: linguagem, estilo, tradução, análise contrastiva, estilística, ironia, humor, cultura, texto-fonte, texto-alvo, recepção, fidelidade, legibilidade, criatividade.
\end{abstract}

Abstract: This article is about the understanding of the role that language plays in the achievement of textual meaning and effect. In order to do that, extracts of Arnon Grunberg's De joodse messias were analised. The main objective was a stylistic comparison between the Dutch novel and a translation in Portuguese. The irony and other themes which occur in the Dutch literature such as the Jew's identity and the Second World War are not easy to traslate. It was explored the way in which these specific elements of the Dutch culture could be received by the Portuguese readers. Finally, the quality of the translation has been assessed in a critical perspective.

Keywords: language, style, translation, contrast analysis, stylistics, irony, humour,culture, source text, target text, reception, fidelity, legibility, creativity. 
Quando se analisa o estilo de um texto é necessário examinar as escolhas linguísticas que estão intrinsecamente ligadas ao significado e ao efeito desse texto no leitor. Nesta perspectiva, os aspectos gramaticais e lexicais poderão ser relevantes para a análise do significado de um determinado texto e do seu estilo. Este trabalho visa a compreensão da parte que a linguagem desempenha na criação de significado e efeito textuais. Para tal, analisei extractos da obra neerlandesa De joodse messias de Arnon Grunberg. A tradução deste romance foi publicada em Portugal em Maio de 2007. Segundo a crítica literária, Arnon Grunberg é considerado um fenómeno desde a sua estreia literária em 1994. As suas obras estão traduzidas em mais de dez idiomas, entre os quais o Português, e receberam alguns dos mais prestigiados prémios literários holandeses.

A escolha deste romance deve-se a várias razões. Em primeiro lugar, trata-se de um exemplo de literatura neerlandesa contemporânea de um autor que tem uma posição cada vez mais forte no palco literário internacional. Em segundo lugar, o romance tem um estilo provocador que será interessante analisar como é transposto para uma tradução em Português. De acordo com as reaç̧ões da imprensa, trata-se de um romance "provocador e satírico" (18 de Maio de 2007). Por um lado, está repleto de sentimentalismo, crueldade e tragicidade, mas, por outro lado, contém uma forte dose de ironia. Aspectos que aparentemente se opõem, mas que também podem surgir interligados. Estes efeitos estilísticos não são fáceis de reproduzir numa tradução. Em terceiro lugar, a comparação deste romance neerlandês com uma tradução em Português poderá fornecer indicações acerca da eventual recepção da literatura neerlandesa em Portugal.

Assim, será interessante investigar o modo como certos elementos específicos da cultura holandesa poderiam ser recebidos pelos leitores portugueses. Elementos como a identidade dos judeus e a Segunda Guerra Mundial são temas recorrentes na literatura neerlandesa. $\mathrm{O}$ mesmo não se pode dizer acerca da literatura 
portuguesa. À excepção do Diário de Anne Frank, um dos livros neerlandeses mais lidos em Portugal, não existem quase nenhuns autores de literatura neerlandesa do Holocausto traduzidos em Português. Esta falta de recepção por parte do público português poderá, segundo Arie Pos, dever-se ao regime de Salazar de ditadura e de aparente neutralidade que terá suscitado pouco interesse por este tipo de literatura. Além disso, julgo que a receptividade é menor em relação a algo que não teve uma relação directa com as experiências do povo português. Ora a maioria dos escritores neerlandeses, autores de literatura do Holocausto viveram na parte ocupada. Autores judeus que sobreviveram nos campos de concentração, tais como G.L.Durlacher e Abel Herzberg, ou autores que viveram escondidos durante a guerra, tais como Andreas Burnier, tentaram explicar as razões da catástrofe e testemunharam como sobreviventes sobre o que aconteceu. Também escritores da segunda geração como Ischa Meijer, Carl Friedman e Myriam Guensberg reagiram aos traumas dos seus familiares e escreveram sobre as suas próprias frustações resultantes da guerra. Nenhuns destes escritores estão traduzidos em Português. Como Portugal foi um dos países que não foi ocupado durante a Segunda Guerra também não teve experiências desse acontecimento para serem testemunhadas. O escritor neerlandês Leon de Winter está, por exemplo, traduzido em Português com a sua obra Serenata (1997), que foca o trauma da Segunda Guerra. Mas os seus Verzamelde verhalen (1993), em que ele explora o contacto com o judaísmo da Europa central e de leste, não estão traduzidos. Em muitos casos, a identidade dos judeus é um tema bastante recorrente na literatura neerlandesa. $\mathrm{O}$ romance de Grunberg que escolhi para análise aborda também esse tema e o do Holocausto, mas de uma forma peculiar que poderá despertar mais o interesse de públicos de países que não tiveram uma relação directa com o Holocausto. Grunberg reescreve o Holocausto de forma subversiva, provocadora e extremamente irónica, onde os judeus passam a ser os criminosos e os palestinos passam a ser as vítimas. Ao estabelecer a ponte entre a identidade 
dos judeus e o conflito israelo-árabe, confere ao seu romance um carácter bastante actual e terá despertado mais interesse por parte das editoras e leitores portugueses.

Este artigo tem então como objectivo uma comparação ao nível estilístico entre a obra original acima referida e a respectiva tradução em Português de Susana Canhoto, Leonor Duarte, Catarina Pires e Arie Pos. Mais concretamente, serão analisados os meios linguísticos que contribuem para a reprodução do estilo do autor do texto-fonte no texto-alvo. Esta análise terá como base teórica as listas utilizadas por Short (1996: 350-53) na exploração do estilo de poesia e prosa. Nesta análise contrastiva será dada uma atenção especial à transposição do estilo irónico de Grunberg na tradução portuguesa. Por fim, procurarei avaliar a qualidade da tradução numa perspectiva crítica, tentando dar respostas às perguntas: até que ponto é que a "artistic function" (Leech \& Short 1981:15) do texto-fonte é reflectido no texto-alvo? A tradução ficou mais próxima do texto-fonte ou foi mais adaptada à cultura do texto-alvo?

A análise contrastiva que proponho terá como base a metodologia de Short. Antes de referir as vantagens desta metodologia, convem primeiro elucidar sobre as bases em que assenta. Com efeito, esta metodologia segue a linha das ideias de Leech e Short (1981:10-73) sobre a análise do estilo na prosa. Estes dois teóricos propõem uma noção de estilo como uma escolha que um determinado autor faz a partir de um reportório de meios linguísticos a fim de atingir uma determinada "artistic function" (Leech \& Short 1981:15). Leech e Short lançam bases importantes para uma análise do estilo do texto literário. Como não há maneira de saber com antecedência que partes da linguagem serão exploradas de forma estilisticamente interessante, os teóricos citados criaram "checklists of style markers" (listas de marcadores de estilo), características particulares do estilo de um texto, que orientam a sua exploração.

Estas ideias estão na base da metodologia que proponho usar neste trabalho. Short aplicou a metodologia de Leech e Short, concretizando-a em termos práticos e confirmando a sua importância. 
Estas listas contêm "marcadores de estilo" (lexicais, gramaticais, etc) que serão tidos em conta na exploração linguística do texto, fornecendo pistas para encontrar características significativas, produtoras de um determinado efeito. A vantagem desta metodologia é que ajuda o leitor/tradutor a interpretar um texto de forma mais alerta e a colmatar algumas falhas de interpretação resultantes de uma primeira leitura intuitiva do texto. Durante a leitura do texto, o leitor/tradutor poderá não reparar em certas características estilísticas, poderá não ter um entendimento adequado sobre o funcionamento da língua ou poderá faltar-lhe uma terminologia para o interpretar. É aqui que entra a metodologia das "checklists" que faculta uma análise bastante completa dos elementos linguísticos utilizados por um autor. Uma língua é constituída por um reportório de possibilidades que é infinito. A meu ver, Short sistematizou de forma prática e clara os elementos linguísticos que devem ser tidos em consideração para a análise do estilo de um determinado texto. Poderão ser um bom instrumento de trabalho para a interpretação que um tradutor deve fazer antes de começar a traduzir. Além disso, esta metodologia é uma das mais recentes nesta área.

Um outro aspecto importante para analisar o estilo de um texto em prosa são as escolhas que os autores fazem para representar o discurso e o pensamento das personagens. Segundo Short (1996:288319) são seis as categorias de representação do discurso: representação de acção por parte do narrador, representação de discurso por parte do narrador, representação de actos de discurso, discurso directo, discurso indirecto e discurso indirecto livre. Paralelamente a estas categorias, existem outras que embora semelhantes, produzem efeitos diferentes. São as chamadas categorias de representação do pensamento: representação de pensamento por parte do narrador, representação de actos de pensamento, pensamento directo, pensamento indirecto e pensamento indirecto livre. Uma vez que o pensamento directo e o pensamento indirecto livre podem ter efeitos diferentes, a análise da representação do discurso e da representação do pensamento serão feitas separadamente. 
Tal como já foi dito na introdução, as escolhas linguísticas podem dar indicações sobre o estilo e o significado de um determinado texto em prosa. As características linguísticas pertencem a áreas diferentes: por exemplo léxico e gramática. Estas características surgem numa lista criada por Leech e Short (1981: 75-82).

$\mathrm{Na}$ área do léxico explorar-se-ão, a nível geral: vocabulário simples ou complexo, geral ou específico; utilização do sentido denotativo ou conotativo; palavras pouco usuais (ex: vocabulário especializado); divisão das palavras em campos semânticos. A nível específico, explorar-se-ão: nomes (abstractos ou concretos, próprios ou comuns); adjectivos (atributos físicos, emocionais, visuais, etc); verbos (frequência de ocorrência; transitivos, intransitivos; estáticos ou dinâmicos; referem movimento físico, estados psicológicos ou actividades; presente ou passado); advérbios (frequência de ocorrência; de modo, de lugar, de tempo, etc).

$\mathrm{Na}$ área da gramática, em termos gerais, observar-se-á se existem construções gramaticais com efeitos especiais (ex: construções comparativas ou superlativas, paralelismos, etc). Em termos específicos, analisar-se-á a estrutura das frases (afirmativas, interrogativas, comandos; longas ou curtas) e das orações (subordinadas ou coordenadas).

$\mathrm{O}$ primeiro fragmento a ser analisado pertence ao capítulo 12 ("Uma ratazana moribunda", pgs. 103-109) da obra em estudo. Diz respeito ao momento após a circuncisão de Xavier, a personagem principal. Nele são descritos os efeitos negativos que tal acto tem para a saúde de Xavier: a dor não pára de aumentar, o sangue também vai alastrando, dando sinais de risco de infecção. Estes sintomas seriam facilmente detectados por um profissional, mas como a circuncisão foi feita por um homem incompetente, Xavier corria perigo. $\mathrm{O}$ autor pretende provavelmente pôr em evidência o ridículo da situação: Xavier deseja consolar o sofrimento dos outros, principalmente dos judeus, mas não consegue suportar a sua própria dor.

Após esta breve contextualização, passemos à análise estilística. Verificou-se ao nível lexical algumas alterações nos tempos das formas verbais. É dada no texto-alvo uma preferência ao uso do P. 
Perfeito ou do P. Imperfeito em vez do P.Mais-que-perfeito. Esta diferença foi registada duas vezes:

TF: [...] had hij later tegen Awromele gezegd. (tinha dito mais tarde a Awromele) (pg.102)

TA: [...] disse mais tarde a Awromele. (pg.103)

TF: [...] triomfantelijker dan hij zich in jaren had gevoeld. (triunfante como não se tinha sentido há anos) (pg.106)

TA: [...] triunfante como não se sentia há anos. (pg.107)

De resto, não se verificam mais alterações ao nível lexical das formas verbais.

No que diz respeito ao vocabulário deste fragmento, saliente-se a forma como certas expressões são traduzidas e no tipo de vocabulário humorístico. Verifica-se no texto-alvo a utilização do itálico em palavras como: mazzeltov, slivovitz, fitness e hall. As duas primeiras pertencem ao campo semântico da cultura e religião judaicas. A razão pela qual o significado de mazzeltov está inserido numa nota de rodapé deve-se ao facto desta palavra não ser compreendida pelos leitores portugueses. Trata-se, aliás, de uma norma frequentemente usada pelos tradutores em Portugal.

Já a palavra slivovitz não necessita de uma nota de rodapé, uma vez que o seu significado se encontra explícito na fala do senhor Schwartz. Ele mesmo explica que se trata de uma bebida feita à base de ameixas e álcool que serve para revigorar uma pessoa. $\mathrm{O}$ nome desta bebida surge na tradução portuguesa com mais uma particularidade. Em vez de slivovitsj como no texto-fonte, surge com uma terminação diferente no texto-alvo: sj dá lugar a z. Esta alteração poderá ser uma adaptação de carácter fonético, de modo a que os leitores portugueses possam ler a palavra com mais facilidade.

Algumas palavras têm tendência a manterem-se na língua portuguesa como estrangeirismos, como é o caso de fitness. Enquanto 
que esta palavra da cultura anglo-saxónica já entrou no vocabulário do dia-a-dia dos holandeses, em Portugal nota-se uma certa resistência em aceitá-la no vocabulário escrito. A palavra hall foi a opção escolhida pelos autores do texto-alvo para traduzir vestibule (vestíbulo). Esta opção é o resultado de uma tentativa de adaptação à cultura portuguesa. Normalmente não se usa tanto em Português o termo vestíbulo para a entrada da casa. O termo hall há muito que foi introduzido no vocabulário português, principalmente oral. No Dicionário da Língua Portuguesa Porto Editora ( $8^{\mathrm{a}}$ edição) surge como: palavra inglesa que significa átrio, vestíbulo. A contrariar um pouco a tendência da falta de aceitação de estrangeirismos na língua portuguesa, a palavra hall surge no vocabulário português como se tratasse de um termo português.

$\mathrm{O}$ vocabulário utilizado no texto-alvo adquire, por vezes, um tom mais humorístico do que o do texto-fonte. Por exemplo, a expressão em Neerlandês goten in de mond (deitar para a boca) foi traduzida por despejar na goela. Considero a expressão usada pelos tradutores muito mais cómica do que a usada no original. Um outro exemplo do mesmo tipo é com a palavra bokkig (intratável, obstinado) que é traduzida por casmurro. Estas palavras inseremse num comentário irónico do narrador a propósito da dor, comparando-a a um amante que fica casmurro quando não recebe a atenção do outro amante. A opção dos tradutores por casmurro torna o comentário do narrador mais humorístico e irónico do que se tivesse usado os termos intratável ou obstinado. Veja-se um outro exemplo: uitschreeuwen (gritar) é traduzido por uivar de dor. Considero que esta escolha também exprime mais humor do que no texto original. Além disso, estes exemplos revelam uma tentativa de adaptar a ironia e o humor à cultura portuguesa.

Um outro aspecto que chama a atenção na comparação entre o texto em Neerlandês e o texto em Português é o modo como determinadas expressões foram traduzidas. Assim, logo na primeira página surge um exemplo de uma expressão que foi adaptada à língua portuguesa: 
TF: Waar hebben ze het toch over [...] (à letra: De que estão a falar) (pg.102)

TA: De que raio estão a falar [...] (pg.103)

Os tradutores optaram por reforçar a frase com a palavra raio, conferindo mais vivacidade e emoção às palavras de Xavier. Além disso, até acentua mais a ironia do pensamento que Xavier teve. Ele não entende a conversa entre Awromele e o senhor Schwartz, apesar de já ter tido algumas aulas de iídiche.

Por vezes, nota-se a necessidade que os tradutores tiveram de traduzir uma expressão com mais palavras. Veja-se o seguinte exemplo:

TF: Meneer Schwartz was uitgeschoten.

TA: O senhor Schwartz cortara de mais com a faca porque não conseguira controlar a mão e fazer um corte direitinho. (pg.103)

É curiosa a forma como a expressão é traduzida. Quatro palavras no texto-fonte dão lugar a vinte palavras no texto-alvo. Esta diferença no número de palavras poderá ser devida ao facto de em Português não existir propriamente um termo para uitgeschoten. Daí a necessidade dos tradutores em desmontar esse termo em mais palavras, criando mais ou menos o mesmo efeito e tentando não se desviar do significado desse termo. Trata-se de uma "explicitação" (Chesterman 2004:258) que tem como objectivo acrescentar elementos que no texto-fonte surgem apenas implícitos.

Ao longo do fragmento também foi possível detectar algumas diferenças na forma como certas expressões foram reproduzidas na língua do texto-alvo. Atentando na seguinte expressão:

TF: 'Ik moest er even in komen.' (à letra seria mais ou menos: tive que voltar a habituar-me) (pg.103) 
TA: Custou-me um pouco a apanhar o jeito. (pg.104)

vemos que er in komen (habituar-se) foi substituído por apanhar o jeito que se adapta melhor à língua do texto-alvo. Além disso, esta opção em Português possui um tom mais humorístico do que uma tradução mais literal. Não contraria, portanto, o efeito humorístico característico do autor original.

Por fim, refira-se mais um exemplo em que houve uma necessidade de acrescentar mais palavras no texto-alvo:

TF: 'Het doet even pijn [...] (à letra: por uns instantes dói) (pg.108)

TA: Sim, claro que durante uns instantes dói. (pg.108)

Quatro palavras são traduzidas com sete palavras. As palavras sim e claro dão mais ênfase à afirmação do senhor Schwartz. Uma tradução mais literal soaria provavelmente menos convincente para os leitores portugueses.

Destaque-se ainda a expressão:

TF: Toen viel hij op de grond. (à letra: depois caiu no chão) (pg.105)

TA: E caiu redondo no chão. (pg.107)

A adição da palavra redondo à expressão em Português exprime mais humor do que se apenas se disser cair no chão. Existem pois alguns momentos em que os tradutores optam por acrescentar determinados elementos a fim de produzir um efeito mais intenso. No caso acima transcrito, a palavra redondo poderá realçar mais o sofrimento de Xavier. Por outro lado também contem um efeito mais humorístico. 
No que diz respeito à representação do discurso, constata-se o uso de sinais diferentes para assinalar o discurso directo, mais variedade e posições diferentes dos verbos introdutores do discurso. A mudança de posição desses verbos para o início ou para o fim das partes representadas por discurso directo acarreta algumas consequências para o modo como a estrutura frásica e a pontuação são apresentadas. Principalmente nos momentos em que os verbos do discurso são colocados após os travessões, há uma tendência no texto-alvo para a utilização de uma só frase, enquanto que no textofonte há duas. Vejam-se então os seguintes trechos:

TF: 'Natuurlijk,'zei meneer Schwartz. Hij strompelde de kamer uit. (pg.103)

TA: - Claro - anuiu o senhor Schwartz e saiu cambaleante do quarto. (pg.104)

TF: 'Ik heb nog een rietje gevonden,' zei hij. Hij hield het rietje triomfantelijk omhoog. (pg.103)

TA: - Até encontrei uma palhinha! - anunciou e elevou a palhinha, com ar triunfante. (pg.104)

TF: 'Dat gaat over,'zei Awromele. 'Het hoort erbij.' En hij kneep weer in Xaviers hand. (pg.104)

TA: - Isso passa. Faz parte - respondeu Awromele e voltou a beliscar a mão de Xavier. (pg.105)

Em todos estes exemplos, o verbo introdutor do discurso em Português é seguido da conjunção coordenativa copulativa e que introduz a oração seguinte, enquanto que no texto-fonte há mais separação entre as frases. Isto poderá afastar-se um pouco do ritmo do texto original, mas creio que não implicará grandes alterações ao nível da representação do discurso.

De resto, considero que o efeito geral irónico que predomina no fragmento original foi preservado no fragmento traduzido. Notase, por vezes, uma certa adaptação do vocabulário humorístico à 
cultura do público-alvo, mas a essência do fragmento original mantem-se. A ironia, muitas vezes expressa sob a forma de humor, foi reproduzida fielmente.

O próximo fragmento a ser analisado insere-se no capítulo 35 ("Inxalá", pgs. 359-367) e diz respeito à operação de tortura do egípcio. O egípcio Nino é dono do restaurante de shoarma "Jerusalém", no qual vende não só bolinhas de falafel, mas também álcool e droga, ilegalmente. Um dia, o egípcio é visitado por dois membros do serviço de informação sionista. Eles querem que ele se torne informante deles; oferecem-lhe respeito, dinheiro e mulheres. Um dos membros é uma mulher israelita que é prostituta. Essa mulher terá relações sexuais com Nino, sendo esse acto filmado pelo outro membro. Dessa maneira têm uma prova de chantagem contra ele. No dia seguinte, o egípcio vai cedo para o restaurante, na esperança de voltar a ver a mulher israelita. Mas em vez dela, aparecem três homens, membros do movimento palestino. Primeiro, ameaçam matá-lo, por ele se ter tornado informante para os judeus e depois fritam-lhe os pés em óleo a ferver. Esta passagem foi escolhida por ser uma boa amostra da ironia cruel e ao mesmo tempo humorística de Grunberg. Com efeito, trata-se de uma cena com uma descrição crua, realista e detalhada de um acto de extrema violência, mas que não deixa de ter algum humor. Vejamos como estes efeitos são alcançados através dos meios linguísticos.

De uma maneira geral, não foram observadas grandes diferenças no primeiro fragmento entre o texto-fonte e o texto-alvo. Em relação ao segundo fragmento há mais desvios a registar. Assim, iniciando a comparação entre os verbos, verifica-se que, uma ou outra vez, é dada preferência por parte dos tradutores pelo uso do P. Perfeito em vez do P. Mais-que-perfeito. Veja-se o seguinte trecho com três formas no P.Mais-que-perfeito no texto-fonte e com apenas uma forma no P.Mais-que-perfeito no texto-alvo:

TF: dacht hij aan de vrouw die hij had verwacht, de vrouw die niet was gekomen, in plaats daarvan waren 
drie heren gekomen. (à letra: pensou na mulher que tinha esperado, a mulher que não tinha vindo, em cuja vez tinham aparecido três homens) (pg.377)

TA: pensou na mulher que tinha esperado, a mulher que não veio, em cuja vez apareceram três homens. (pg.365)

Uma vez mais fica-se com a impressão de que os acontecimentos narrados no texto-alvo com o P. Perfeito parecem ter ocorrido a uma menor distância temporal, se comparados com os do textofonte. Este desvio não terá em princípio grandes implicações ao nível do fragmento no seu todo.

Um outro aspecto observado ao nível da classe lexical dos verbos é a já referida preferência pelo uso de mais construções activas do que passivas no texto-alvo:

TF: Hij werd in zijn gezicht geslagen. (à letra: Ele foi batido na cara) (pg.372)

TA: Levou umas bofetadas na cara. (pg.361)

Neste caso, não faria de facto muito sentido usar uma construção passiva, visto que normalmente em Português, nesta situação, não é usual a utilização do verbo ser. Refira-se ainda que a expressão na cara se torna redundante no texto-alvo, uma vez que o acto levar bofetadas ou esbofetear já pressupõe que é na cara.

Um outro exemplo é:

TF: werd er geklopt (à letra: foi batido à porta) (pg.375)

TA: bateram à porta (pg.363)

Neste caso não seria apropriada em língua Portuguesa a utilização da passiva. 
O que foi constatado como mais significativo em relação aos verbos foi o facto de no texto-alvo alguns deles terem sido omitidos. Nota-se, aliás, uma grande discrepância no número de verbos: no texto-fonte 495 e no texto-alvo 469 . Foram omitidos ou não conjugados, por exemplo, os seguintes verbos: calados, sem emitir um único som (pg.360) em vez de ze zwegen, ze maakten geen geluid (estavam calados, não emitiam nenhum som); sem partir nenhum dente (pg.363) em vez de brak hij geen tand (não partiu nenhum dente); alguém com uma febre alta (pg.363) em vez de iemand die hoge koorts heeft (alguém que tem uma febre alta); com sola de couro (pg.364) em vez de de zolen waren van leer (as solas eram de couro).

Estas omissões não se observam apenas ao nível da classe lexical dos verbos, mas também ao nível do vocabulário em geral. Com efeito, surge com menos frequência a tendência para a repetição de palavras do texto-fonte. Ou os tradutores optam por evitar repetir determinadas palavras, ou escolhem substitui-las por outras. Vejamos alguns casos em que se optou no texto-alvo por evitar a redundância: tomaram-na (o pronome pessoal complemento substitui decisão; esfregou a pistola pelos lábios (o cano é omitido); situação curiosa em que se encontravam (o sujeito do verbo é omitido); onde eles tinham estado sentados (eles está em vez de os homens); o que tinha a pistola (o pronome pessoal substitui o homem); em comparação com a deles (o pronome pessoal a substitui a dor); por fim, a frase de uma só palavra no texto-fonte Hij trappelde (Esperneava) é totalmente omitida.

Existem outros exemplos em que se verifica mais uma substituição de palavras por sinónimos como forma de evitar a repetição: coisa boa/petisco (no original apenas coisa boa); estúpido/burro/besta-quadrada (no original apenas estúpido); indigno/sem dignidade (no original apenas indigno); mijar/urinar (no original apenas mijar). Se, por um lado, o uso de menos repetições pode facilitar a leitura em Português, por outro lado, não segue o estilo do autor do texto original e atinge um menor efeito. Se as repetições 
são um meio linguístico usado por Grunberg a fim de dar ênfase a determinados aspectos e para exprimir uma certa ironia e humor, ao evitá-las poderemos estar a perder um pouco esse efeito.

Além disso, a menor frequência de repetições e as omissões verificadas no texto-alvo nem sempre foram efectuadas com consistência. Por exemplo, o verbo plassen aparece quase sempre traduzido por mijar, mas a uma dada altura surge urinar. $\mathrm{O}$ adjectivo estúpido em vez de aparecer seis vezes repetido, aparece apenas por duas vezes, sendo substituído por burro e besta-quadrada. Esta aparente incoerência poderá ser o resultado de uma tentativa de provocar mais humor, adquirindo, assim, alguma razão de ser na língua da cultura do texto-alvo.

Outros casos foram observados em que se verifica o contrário, isto é, uma tendência no texto-alvo para acrescentar certos elementos que não constam no texto-fonte: o cano da pistola (no textofonte apenas pistola); Eram uns bonitos sapatos pretos (no original sem verbo). Porém, estes exemplos não constituem um desvio que acarrete consequências para a compreensão do trecho no seu todo, visto que não ocorrem com frequência.

Ainda no âmbito do vocabulário, saliente-se a forma como alguns elementos culturais foram transpostos para a cultura portuguesa. Do vocabulário pertencente ao campo semântico da cozinha surgem termos no texto-fonte, tais como shoarma e bolinhas de falafel, que são de origem israelita e que também fazem parte da cultura holandesa. Apesar da sua origem não ser propriamente holandesa, este tipo de comida israelita tornou-se muito popular na Holanda. Em Portugal é um pouco menos conhecido. Daí esses termos ocorrerem no texto-alvo devidamente assinalados em itálico. Uma nota do tradutor para clarificar estes termos não foi necessária, uma vez que o seu significado se depreende do contexto.

Por fim, refira-se a forma interessante como as palavras e expressões cassetterecorder (gravador de cassetes) e miste (sentia a falta) foram traduzidas: aparelhagem e sentia saudades, respectivamente. A primeira é adaptada ao tempo mais moderno (2007) 
em que este romance é lido pelo público português. Já quase não se usam gravadores de cassetes. Além disso, o termo aparelhagem é mais comum em Português. A segunda

expressão, que também poderia ter sido traduzida por sentir a falta foi antes traduzida por sentir saudades. Trata-se de um modo de exprimir sentimentos exclusivamente português que neste trecho surge bem enquadrado e mais próximo da cultura portuguesa.

Voltando agora a atenção para a representação do discurso, foram detectados alguns desvios que não tinham sido verificados no outro fragmento. No fragmento em análise a posição dos verbos introdutores do discurso é a mesma encontrada no texto-fonte, ou seja, entre as falas das personagens em discurso directo. À partida, esta alteração não implica grande transtorno na leitura. No entanto, deveria ter havido mais consistência no posicionamento desses verbos.

É chegado o momento de tecer algumas conclusões acerca da análise contrastiva efectuada. Segundo Leuven-Zwart (2004: 30110), com a ajuda de uma comparação de uma tradução com o seu texto original é possível detectar as normas que os tradutores seguiram e o significado que deram a essas normas. De acordo com esta teórica, o tradutor poderá basear-se em critérios como: literalidade, fidelidade ao texto original, legibilidade e criatividade (Leuven-Zwart 2004: 301-10). Importante será ver se aplicaram algumas dessas normas de forma coerente, bem como analisar o que isso significa para a tradução e para a sua relação com o texto original.

Tendo partido de um modelo de comparação, propus-me ao longo deste trabalho detectar os casos em que a expressão do estilo do texto traduzido se afasta ou se aproxima do estilo correspondente no texto original. Baseando-me nas listas de análise de Short, procurei analisar que meios linguísticos (léxico, gramática, representação do discurso) contribuíram para a reprodução do tom irónico de Grunberg, comparando ambos os textos. Vimos muitas vezes que essa ironia assumia outras facetas, nomeadamente o humor. 
Tanto a ironia como o humor são elementos que são sempre específicos de uma determinada cultura cuja reprodução numa outra cultura nem sempre é tarefa fácil. No caso concreto do romance De joodse messias a ironia foi usada para uma análise da história da humanidade. O escritor liga o tema do sofrimento da humanidade a motivos que são uma constante nas suas obras, tais como a identidade judaica e o holocausto. No romance em análise parece que assistimos à descrição de um holocausto ao contrário: os judeus são desta vez consolados e os palestinos sofrem. Os fragmentos escolhidos para análise são uma pequena amostra desta temática. Assim, Xavier decide fazer uma circuncisão, como forma de adesão ao judaísmo. Ele convence-se cada vez mais que é um messias que veio ao mundo para salvar os judeus. Este messianismo poderá ser equiparado ao de Hitler no tempo na Segunda Guerra Mundial. Mas desta vez seria um messias para salvar os judeus. Nino, o egípcio, é torturado pelos sionistas israelitas, por apoiar a causa dos palestinos. Estes passam a ser as vítimas e os judeus passam a ser os criminosos.

Dados o realismo, a crueza e a ironia com que estes eventos foram narrados, Grunberg transformou muitas vezes a sua ironia em humor, provavelmente para suavizar a violência dos episódios e para atenuar a sentimentalidade. De uma maneira geral, esta ironia disfarçada sob a forma de humor e este humor disfarçado de ironia foram reproduzidos fielmente no texto-alvo. Poder-se-á dizer que os tradutores se basearam na norma da fidelidade ao texto original (Leuven-Zwart 2004: 301-10). É certo que foram encontrados alguns desvios linguísticos, por exemplo ao nível lexical e do discurso. Ao evitarem, como vimos, a repetição de certas palavras, substituindo-as por outras mais formais, significa que os tradutores interpretaram, por vezes, alguns aspectos com mais seriedade e formalidade, afastando-se um pouco do estilo humorístico do texto original. O posicionamento dos verbos introdutores do discurso nem sempre ocorreu de forma consistente. Notou-se também no texto-alvo uma certa preferência por determinados tempos 
verbais. Porém, não considero que esses pequenos desvios possam ter consequências para a reprodução do estilo no seu todo. Isso só aconteceria se mais desvios desse tipo tivessem sido constatados; se, por outras palavras, tivesse havido uma grande frequência e consistência nesses desvios.

Alguns elementos culturais nem sempre foram transpostos para a cultura do texto-alvo da mesma maneira. Constatámos, por exemplo, que aspectos da religião e cultura judaicas (slivovitz, mazzeltof, falafel, shoarma) foram adaptados através de estratégias tais como o itálico, a nota do tradutor, ou alterações fonéticas de palavras no texto-alvo. À excepção do termo mazzeltof que é explicado com uma nota do tradutor, os outros não deixam de manter o seu carácter exótico, mantendo-se assim a cultura judaica no texto-alvo. O que julgo que poderá ser positivo em termos de receptividade. Mantem acesa a curiosidade do público português e poderá levá-los a interessarem-se pelo assunto e a pesquisarem mais.

A norma da legibilidade (Leuven-Zwart 2004: 301-10) foi também seguida. Os três fragmentos estão muito bem escritos em Neerlandês e esse aspecto também é visível no texto em Português. O estilo fluido, efervescente é espelhado no texto traduzido. Os acontecimentos são narrados de forma bastante detalhada. Por exemplo, são dedicadas muitas páginas à passagem sobre a circuncisão e ao momento após a circuncisão, as quais são lidas com bastante rapidez. No texto-alvo nota-se também a fluidez na passagem de umas frases para as outras, conferindo um ritmo rápido de leitura. Apesar de se ter verificado uma menor repetição do vocabulário no texto-alvo, a minúcia das descrições dos eventos foram também seguidas pelos tradutores. Os desvios verificados ao nível da construção frásica e a modificação de certas expressões no textofonte terão resultado de uma tentativa de adaptação à língua do textoalvo, conferindo assim uma maior legibilidade em Português.

Quanto à norma da criatividade (Leuven-Zwart 2004: 301-10), creio que não foi propriamente uma prioridade na tradução em Português. Poder-se-á falar antes da adaptação de certas expres- 
sões, de certos modos de dizer, à língua e cultura portuguesas, como foi constatado ao longo da análise. Pelo contrário, a tradução ficou mais próxima do texto-fonte.

De tudo o que fica dito, se me perguntarem se se trata de uma boa tradução, a minha resposta é afirmativa. Não apenas por estar bem escrita em Português, seguindo a norma da legibilidade, mas também por ter conseguido reproduzir a "artistic function" (Leech \& Short 1981:15) da ironia do texto original. Algumas diferenças nos meios linguísticos mostraram, por vezes, uma tentativa de adaptar os elementos irónicos e humorísticos à cultura portuguesa, mas sem se afastar da essência do texto original. Os leitores portugueses ficam a conhecer melhor os fantasmas da guerra do passado e do presente através de um exemplo de literatura Neerlandesa contemporânea de grande qualidade e irreverência.

\section{Bibliografia}

AlMEIDA COSTA, J. \& Sampaio e MELO, A. (1999) Dicionário da Língua Portuguesa. Porto Editora.

CANHOtO, Susana en al. (2007) O Messias dos Judeus. Cascais: Bico de Pena.

CHESTERMAN, Andrew "Vertaalstrategieën: een classificatie". In: Koster, Cees en al (2004) Denken over vertalen. Uitgeverij Vantilt.

DIREITINHO, Riço J. (2007) "O consolador de Judeus" In: Público, 18 de Maio 2007.

GRUNBERG, Arnon (2006) De joodse messias. Amsterdam: Rothschild \& Bach. 
LEECH, Geoffrey N. \& Michael H. Short (1981) Style in fiction. A Linguistic Introduction to English Fictional Prose. London/New York: Longman.

LEUVEN-ZWART, Kitty M (2004) “Een goede vertaling, wat is dat?" in: Koster, Cees en al Denken over vertalen. Uitgeverij Vantilt.

SHORT, Mick (1996) Exploring the language of Poems, Plays and Prose. London/New York: Longman. 